\title{
Optical properties of praseodymium doped silver-borate glasses
}

\author{
G.V. Jagadeesha Gowda and B. Eraiah
}

\begin{abstract}
Praseodymium doped silver-borate glasses having composition $x \mathrm{Pr}_{6} \mathrm{O}_{11}-(25-x) \mathrm{Ag}_{2} \mathrm{O}-75 \mathrm{~B}_{2} \mathrm{O}_{3}(x=0,1,2,3,4,5)$ were prepared by conventional melt quenching method. The density, molar volume, and optical energy band gap of these glasses were measured. Optical absorption spectra of these glasses were recorded in the range 300-1000 $\mathrm{nm}$ at room temperature. The refractive index, molar refraction, and polarizability of oxide ion were calculated by using Lorentz-Lorentz relations. The oxide ion polarizabilities deduced from two different quantities, viz. refractive index and optical energy band gap, agree well compared with other glasses. The variation of the preceding optical parameters with respect to praseodymium concentration is explained.
\end{abstract}

PACS No.: 78.66.Jg.

Résumé : Nous préparons, par la méthode conventionnelle de trempe à l'état liquide, des verres au borate d'argent dopés au praséodyme, de composition $x \mathrm{Pr}_{6} \mathrm{O}_{11}-(25-x) \mathrm{Ag}_{2} \mathrm{O}-75 \mathrm{~B}_{2} \mathrm{O}_{3}(x=0,1,2,3,4,5)$. Nous mesurons la densité, le volume molaire et l'énergie de la bande interdite optique. Nous enregistrons à la température de la pièce les spectres d'absorption optique de ces verres dans le domaine 300-1000 $\mathrm{nm}$. Utilisant les relations de Lorentz-Lorentz, nous calculons l'indice de réfraction, la réflexion molaire et la polarisabilité de l'ion d'oxyde. Les polarisabilités de l'ion d'oxyde déduites de deux différentes sources, respectivement l'indice de réfraction et l'énergie de la bande interdite optique, sont en bon accord si on compare avec d'autres verres. Nous expliquons la variation des paramètres optiques étudiés ci-dessus avec la concentration en praséodyme. [Traduit par la Rédaction]

\section{Introduction}

Rare earth doped glasses are considered to be a very important class of photonic materials because of their several inherent advantages over the crystalline materials. In recent years, research on common glasses containing rare earth ions have attracted considerable interest because of the rate at which and the mechanism by which excited states of these ions are formed and decay. These are of great significant in the application of these ions in phosphors, lasers, solar energy concentrators, amplifications and other currently developed electronic devices [1]. It has been stated that there are at least 36 lasing transitions in rare earth doped glass systems [2]. Praseodymium-doped glasses have proved to be effective for several applications in optical devices and solid state lasers [3]. $\mathrm{B}_{2} \mathrm{O}_{3}$ is one of the most common glass formers and is present in almost all commercially important glasses and it is often used as a dielectric material. Borate glasses can be formed over a wide range of modifier concentrations at relatively lower melting temperatures. In borate glasses, $\mathrm{B}_{2} \mathrm{O}_{3}$ is a basic glass former because of its higher bond strength, lower cation size and smaller heat of fusion. Therefore, the structural investigation of boron in these glasses is one of the most attractive factors. In the borate glasses, $\mathrm{B}^{3+}$ ions are triangularly coordinate by oxygen atoms and triangle units are corner bonded in a random configuration [4].

Although boron occurs in both triangular and tetrahedral coordination in crystalline compound, it is believed to occur only in the triangular state in vitreous boric oxide. The structure of vitreous boric oxide is also believed to contain a large concentration of units consisting of three boron-oxygen triangles joined to form a boroxal ring structure [5].

Considering silver oxide with boric acid thus allows tuning of optical properties in a wide range depending on the composition. Consequently, the properties of glasses of the system $\mathrm{Ag}_{2} \mathrm{O}-\mathrm{B}_{2} \mathrm{O}_{3}$ have attracted much interest. Rare earth ions are widely used for lasers and amplifiers. Over the last few decades, great importance has been attached to glasses doped with rare earth and transition metal ions. The present work intends to study the optical properties of rare earth compounds like praseodymium $\left(\operatorname{Pr}_{6} \mathrm{O}_{11}\right)$ doped silver-borate glasses and to discuss the variations of optical properties with respect to a small concentration of $\operatorname{Pr}_{6} \mathrm{O}_{11}$.

\section{Theory}

The absorption coefficient, $\alpha(v)$, in amorphous materials, in the optical region near the absorption edge at particular temperature, obeys the empirical relation known as the Urbach rule [6] given by

$\alpha(\nu)=\alpha_{\mathrm{o}} \exp \left(\frac{h \nu}{E_{\mathrm{c}}}\right)$

where $h \nu$ is photon energy, $\alpha_{\mathrm{o}}$ is a constant, and $E_{\mathrm{c}}$ is an energy, which is interpreted as the width of the localized state in the normally forbidden band gap, which is also known as the Urbach energy.

Optical absorption in solids and liquids occurs in various mechanisms by which the photon energy will be absorbed either lattice or by electrons where the transferred energy is conserved. The lattice (or phonon) absorption will give information about the atomic vibration involved and this absorption of radiation normally occurs in the infrared region of the spectrum. The higher energy parts of the spectrum, particularly those associated with the interband electronic transition, will provide further information about the electron states. In these processes, the electrons are excited from a filled band to an empty band by the photon absorption and as a consequence of this; a marked increase in the absorption coefficient, $\alpha(\nu)$, will result. The onset of this rapid

Received 14 November 2012. Accepted 31 January 2014.

G.V. Jagadeesha Gowda and B. Eraiah. Department of Physics, Bangalore University, Bangalore, Karnataka, India.

Corresponding author: B. Eraiah (e-mail: eraiah@rediffmail.com). 
Table 1. Density, molar volume, optical energy band gap, refractive index, molar refraction and polarisability of $\mathrm{Pr}_{6} \mathrm{O}_{11}-\mathrm{Ag}_{2} \mathrm{O}-\mathrm{B}_{2} \mathrm{O}_{3}$ glasses.

\begin{tabular}{|c|c|c|c|c|c|c|c|c|c|}
\hline \multirow[b]{2}{*}{ Sample ID } & \multicolumn{3}{|c|}{ Glass composition (mol\%) } & \multirow[b]{2}{*}{$\begin{array}{l}\text { Density, } \\
\rho\left(\mathrm{g} / \mathrm{cm}^{3}\right)\end{array}$} & \multirow[b]{2}{*}{$\begin{array}{l}\text { Molar volume, } \\
V_{\mathrm{m}}\left(\mathrm{cm}^{3}\right)\end{array}$} & \multirow[b]{2}{*}{$\begin{array}{l}\text { Energy band gap, } \\
E_{\mathrm{g}}(\mathrm{eV})\end{array}$} & \multirow[b]{2}{*}{$\begin{array}{l}\text { Refractive index, } \\
n\end{array}$} & \multirow[b]{2}{*}{$\begin{array}{l}\text { Molar refraction, } \\
R_{\mathrm{m}}\left(\mathrm{cm}^{3}\right)\end{array}$} & \multirow[b]{2}{*}{$\begin{array}{l}\text { Polarisability, } \\
\alpha_{\mathrm{e}}\left(\mathrm{cm}^{3} ; \times 10^{-24}\right)\end{array}$} \\
\hline & $\mathrm{Pr}_{6} \mathrm{O}_{11}$ & $\mathrm{Ag}_{2} \mathrm{O}$ & $\mathrm{B}_{2} \mathrm{O}_{3}$ & & & & & & \\
\hline A1 & 0 & 25 & 75 & 4.014 & 27.43 & 1.953 & 2.757 & 18.862 & 7.476 \\
\hline $\mathrm{A} 2$ & 1 & 24 & 75 & 3.834 & 31.30 & 2.014 & 2.730 & 21.369 & 8.470 \\
\hline A3 & 2 & 23 & 75 & 4.246 & 29.65 & 2.075 & 2.704 & 20.104 & 7.969 \\
\hline A4 & 3 & 22 & 75 & 3.938 & 33.98 & 2.188 & 2.659 & 22.740 & 9.013 \\
\hline A5 & 4 & 21 & 75 & 4.027 & 22.74 & 2.250 & 2.635 & 15.116 & 5.991 \\
\hline A6 & 5 & 20 & 75 & 4.009 & 37.32 & 2.416 & 2.575 & 24.345 & 9.650 \\
\hline
\end{tabular}

change in $\alpha(\nu)$ is called the "fundamental absorption edge" and the corresponding energy is the "energy gap" [7]. In amorphous materials the absorption due to the band-to-band transitions that determines the optical energy gap was interpreted by Davis and Mott [8] and can be written in general form:

$\alpha(\nu)=\frac{B}{h \nu}\left(h \nu-E_{\mathrm{g}}\right)^{n}$

where $B$ is a constant, $h \nu$ is the photon energy, $E_{\mathrm{g}}$ is the optical energy gap, and $n$ is an index that can have any values between $1 / 2$ and two depending on the nature of the interband electronic transitions [9]. The goodness of the fit of the data to the formula for either $n=1 / 2$ (direct band gap) or $n=2$ (indirect band gap) is determined. It has been found that for many amorphous materials, a reasonable fitting of (2) with $n=2$ is achieved. This is the case of indirect transitions, where the interactions with lattice vibrations take place. To calculate optical band gap $\left(E_{g}\right)$, a graph was plotted between $(\alpha h \nu)^{2}$ and $h \nu$ for each sample and a line was drawn tangent to the point of inflection on the curve. The $h \nu$ value at the point of intersection of the tangent line on the horizontal axis is the band gap $\left(E_{g}\right)[5]$ and Table 1 lists the calculated values of optical band gap.

\section{Experimental}

\subsection{Sample preparation}

Glasses were synthesized having a general formula $(25-x) \mathrm{Ag}_{2} \mathrm{O}-$ $75 \mathrm{~B}_{2} \mathrm{O}_{3}(x=0)$, which is undoped. With praseodymium oxide, doped glasses were synthesized having a general formula $x \operatorname{Pr}_{6} \mathrm{O}_{11}-(25-x) \mathrm{Ag}_{2} \mathrm{O}$ $-75 \mathrm{~B}_{2} \mathrm{O}_{3}(x=0,1,2,3,4,5 \mathrm{~mol} \%)$. A series of glasses were prepared by mixing together the appropriate weights of silver oxide $\left(\mathrm{Ag}_{2} \mathrm{O}\right)$, boric acid $\left(\mathrm{H}_{3} \mathrm{BO}_{3}\right)$, and praseodymium oxide $\left(\mathrm{Pr}_{6} \mathrm{O}_{11}\right)$. Appropriate weights of oxides were weighed on a single pan digital balance having an accuracy of $0.001 \mathrm{~g}$. Repeated grinding of the mixture was done to ensure homogenization. The homogenous mixture was then transferred to porcelain crucibles, which were subjected to melting in an automatically temperature controlled electric furnace, at a temperature ranging from 1000 to $1200{ }^{\circ} \mathrm{C}$, depending on the composition, in an air atmosphere. The resultant melt was then quenched between two copper blocks, a high temperature to room temperature (303 K). After quenching, all samples were immediately transferred to an annealing furnace. Samples were annealed at $250{ }^{\circ} \mathrm{C}$ for $1 \mathrm{~h}$ to relax strains present in quenched glasses during sudden quenching. The glass samples were stored in desiccators to prevent absorption of moisture.

\subsection{X-ray diffraction (XRD)}

The amorphous nature of the samples was confirmed using the $\mathrm{XRD}$ technique and $\mathrm{XRD}$ analysis was carried out at room temperature using a Philips X'pert pro powder X-ray diffractometer by a $\mathrm{Cu}$ anode $\left(\mathrm{K}_{\alpha}, \lambda=1.54439 \AA\right)$ radiation at $45 \mathrm{kV}$ and $30 \mathrm{~mA}$. The scanning angle, $2 \theta$, range was from $10^{\circ}$ to $70^{\circ}$. The XRD spectra of all samples showed the diffused bands characteristic of the XRD pattern of amor- phous materials. The spectra did not show any sharp peaks and this confirms the fact that glass samples are amorphous in nature.

\subsection{Density and molar volume}

The densities of the glass samples $\left(\rho, \mathrm{g} / \mathrm{cm}^{3}\right)$ at room temperature were measured by the Archimedes principle, using toluene as an immersion liquid (density of toluene $=0.8635 \mathrm{~g} / \mathrm{cm}^{3}$ at room temperature)

$\rho=\frac{a}{a-b}$

where $a$ is the weight of the glass sample measured in air, and $b$ is the weight when the glass is immersed in toluene. The molar volume $\left(V_{\mathrm{m}}, \mathrm{cm}^{3} / \mathrm{mol}\right)$ is calculated using

$V_{\mathrm{m}}=\frac{M}{\rho}$

where $M$ is the molecular weight, and $\rho$ is the density of corresponding glass samples [10].

\subsection{Optical absorption}

The optical absorption spectra for these glasses were recorded using Hitachi-U-3200 absorption spectrophotometer in the wavelength region 300-1000 $\mathrm{nm}$ at normal incidence. The optical absorption coefficient, $\alpha(\nu)$, was calculated for each sample at different photon energies using

$\alpha(\nu)=\frac{A}{d}$

where $A$ is the absorbance and $d$ is the thickness of the samples.

\subsection{Refractive index}

Refractive indices of these glasses are calculated by using the formula proposed by Dimitrov and Sakka [11]

$\frac{n^{2}-1}{n^{2}+2}=1-\frac{\sqrt{E_{g}}}{20}$

where $n$ is the refractive index and $E_{g}$ is the energy gap.

\subsection{Molar refraction $\left(R_{m}\right)$ and polarizability $\left(\alpha_{\mathrm{e}}\right)$}

The molar refraction, $R_{\mathrm{m}}$, is

$\left(\frac{n^{2}-1}{n^{2}+2}\right) V_{\mathrm{m}}=R_{\mathrm{m}}$

where $V_{\mathrm{m}}$ is the molar volume and $n$ is the refractive index of the samples. Equation (7) is known as Lorentz-Lorentz equation, which relates the polarizability $\left(\alpha_{\mathrm{e}}\right)$ of oxide ion as follows: 
$\left(\frac{n^{2}-1}{n^{2}+2}\right) V_{\mathrm{m}}=\left(\frac{4}{3}\right) \pi N \alpha_{\mathrm{e}}$

where $V_{\mathrm{m}}$ is the molar volume, $N$ is Avogadro's number $(N=6.023 \times$ $10^{23} / \mathrm{mol}$ ) [12].

\section{Results and discussion}

Figure 1 shows the XRD spectra of praseodymium-doped silver borate glasses. Because there are no sharp peaks in the spectra, it confirms the amorphous nature. Figure 2 shows the variation of density with molar percent of $\operatorname{Pr}_{6} \mathrm{O}_{11}$. As can be seen from the figure, the density is lower for 1 and $3 \mathrm{~mol} \%$ of $\operatorname{Pr}_{6} \mathrm{O}_{11}$ and the density is higher for $2 \mathrm{~mol} \% \operatorname{Pr}_{6} \mathrm{O}_{11}$. Figure 3 shows the variation of molar volume with molar percent of $\operatorname{Pr}_{6} \mathrm{O}_{11}$. Here we can see the lowest molar volume for $4 \mathrm{~mol} \%$ of $\operatorname{Pr}_{6} \mathrm{O}_{11}$. We have observed the significant changes in density and molar volume at 2 and $4 \mathrm{~mol} \%$ of $\mathrm{Pr}_{6} \mathrm{O}_{11}$. These changes occurred due to the structural changes in the glass matrix at those particular concentrations. It is well known that $\mathrm{Pr}^{3+}$ and $\mathrm{Pr}^{4+}$ ions can exist simultaneously in a glass network [13] and because they are $4 \mathrm{f}^{2}$ and $4 \mathrm{f}^{1}$ transitions, respectively, they can contribute to structural changes in the glass matrix; hence the variation of density and molar volume occurred in the glass system. Figure 4 is one of the typical absorption spectra of the glass system. Notably, there is no sharp peak in the spectrum and this indicates that the prepared glasses are amorphous in nature. It is found that the intensities of most of the absorption bands increase with the increase in concentration of rare earth oxides. In the present glass system, the intensity of the ${ }^{1} \mathrm{D}_{2}$ excited state was observed at around $600 \mathrm{~nm}$, and is systematically increasing with concentration of rare earth oxide. It indicates that an increase in rare earth oxide covalence with the addition of $\operatorname{Pr}_{6} \mathrm{O}_{11}$ into glass network and this covalence may influence the structure of glass network [14]. Figure 5 is a typical graph of $(\alpha h \nu)^{2}$ versus $h \nu$. By extrapolation of linear region of the curve to $h \nu$-axis, the energy band gap has been obtained.

The variation of energy band gap is shown in Fig. 5. It is found that energy band gap increases with increasing molar percent of $\operatorname{Pr}_{6} \mathrm{O}_{11}$. The optical band gap obtained in the present glass system is 1.9531 to $2.4166 \mathrm{eV}$, shown in Fig. 6, which is in the same order has reported in the literature [15]. The energy band gap increases not only with increase of molar percent of $\operatorname{Pr}_{6} \mathrm{O}_{11}$ but also with decrease of $\mathrm{Ag}_{2} \mathrm{O}$ molar percent. Hogarth and Gouhri [16] have reported the same trend of results. According to them, addition of divalent oxides depolarizes the glass-forming network. It is generally accepted that the absorption edge depends on the oxygen bond strength in the glass-forming network [17]. This process changes the oxygen bonding in the glass-forming network, and any change of oxygen bonding in a glass network, such as the formation of nonbridging oxygen changes the absorption characteristics. This explains why the absorption edges move toward the higher energies with increasing concentration of $\mathrm{Ag}_{2} \mathrm{O}$ in borate glasses. The calculated refractive index, molar refraction, and polarizability of these glasses are tabulated in Table 1 . The trend of refractive index variation with concentration of rare earth oxide is exactly opposite to the energy band gap as expected. As can be seen from the table, the refractive index decreases with increasing concentration of $\operatorname{Pr}_{6} \mathrm{O}_{11}$. Refractive index mainly depends on the composition of an optical material and molar refraction depends on the polarizability of the material. The more polarizable the outer electrons, the higher the refractive index and the higher the molar refraction as observed in the present glass system.

\section{Conclusion}

Praseodymium-doped silver borate glasses were prepared using the melt quenching method and the amorphous nature of these glasses was confirmed by XRD. Significant changes in density and
Fig. 1. XRD spectra of $\operatorname{Pr}_{6} \mathrm{O}_{11}-\mathrm{Ag}_{2} \mathrm{O}-\mathrm{B}_{2} \mathrm{O}_{3}$ glass.

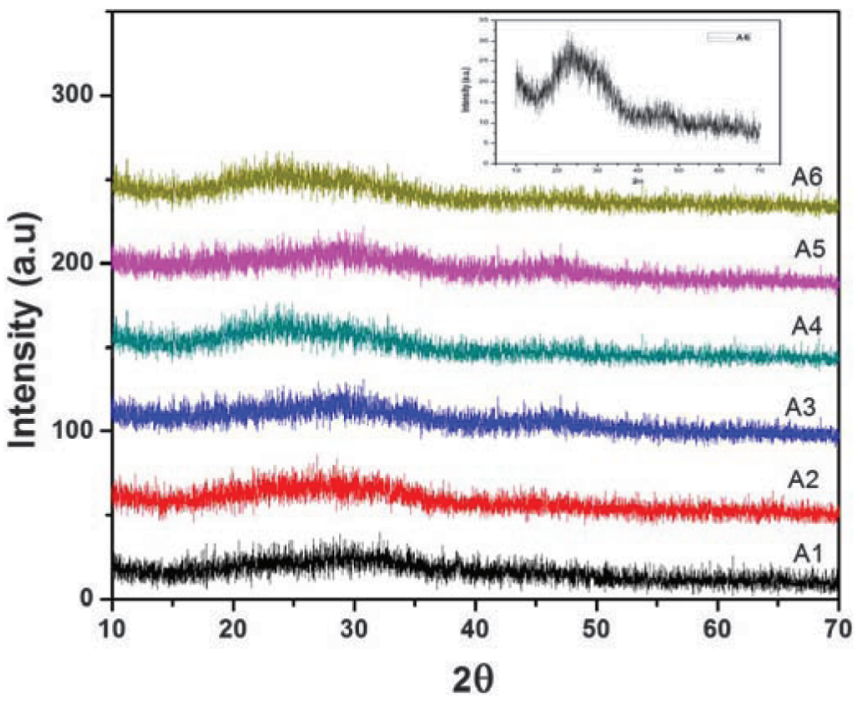

Fig. 2. Density versus molar percent of $\operatorname{Pr}_{6} \mathrm{O}_{11}$.

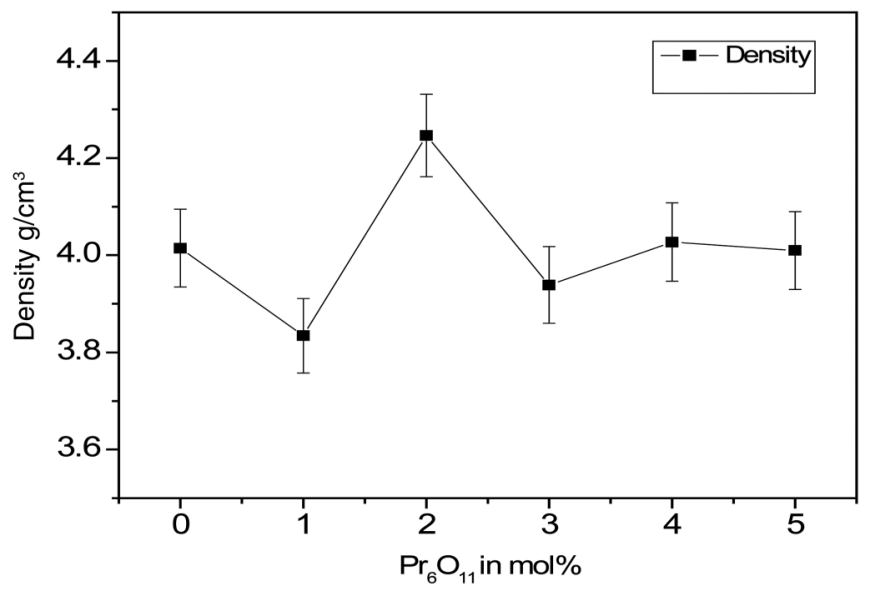

Fig. 3. Molar volume versus molar percent of $\operatorname{Pr}_{6} \mathrm{O}_{11}$.

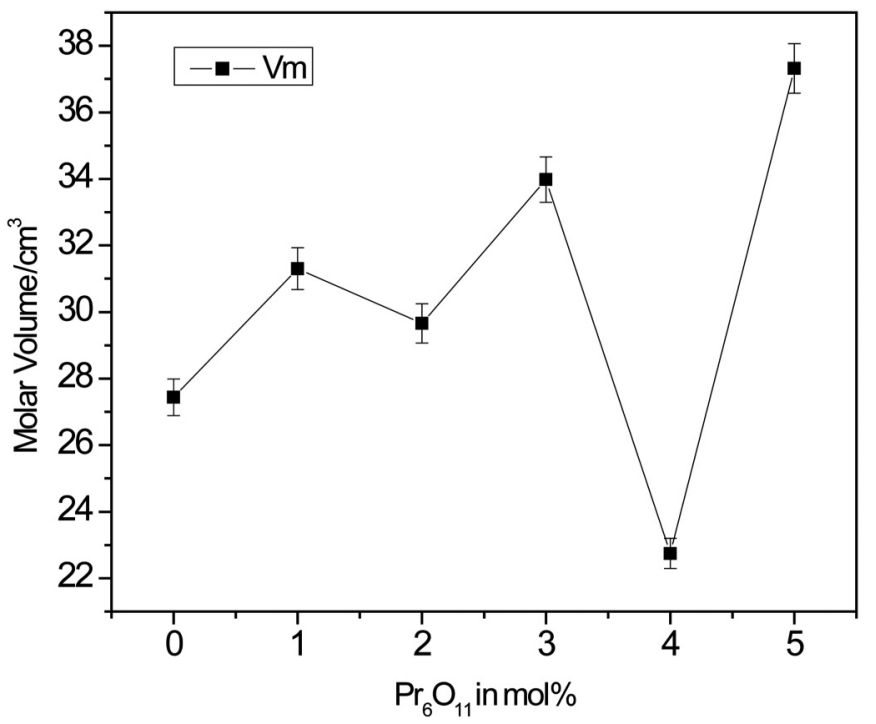


Fig. 4. A typical absorption spectrum of $\mathrm{Pr}_{6} \mathrm{O}_{11}-\mathrm{Ag}_{2} \mathrm{O}-\mathrm{B}_{2} \mathrm{O}_{3}$ glass.

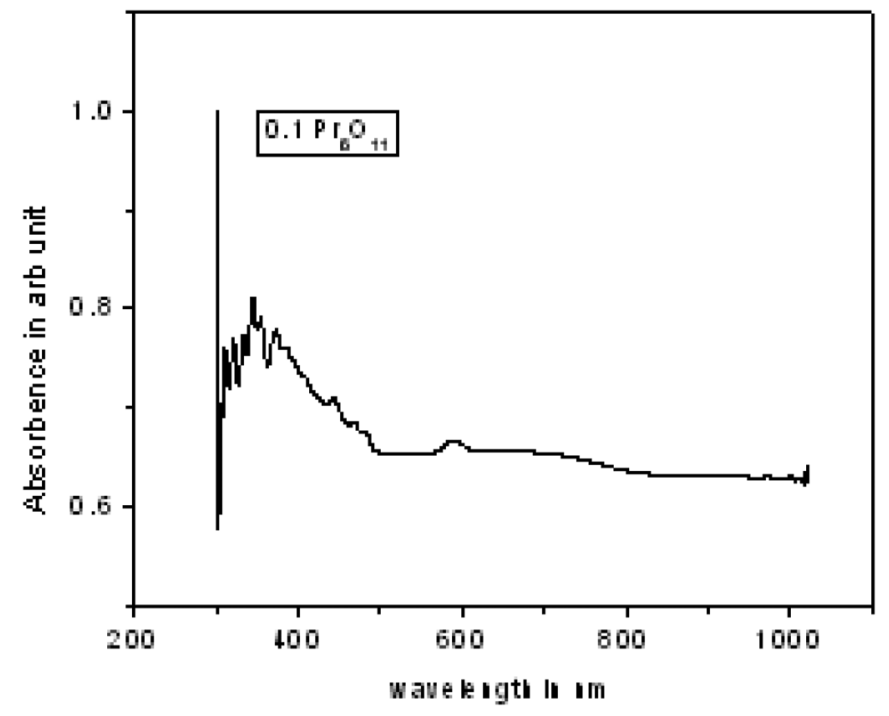

Fig. 5. A typical plot of $(\alpha h \nu)^{2}$ versus photon energy $(h \nu)$.

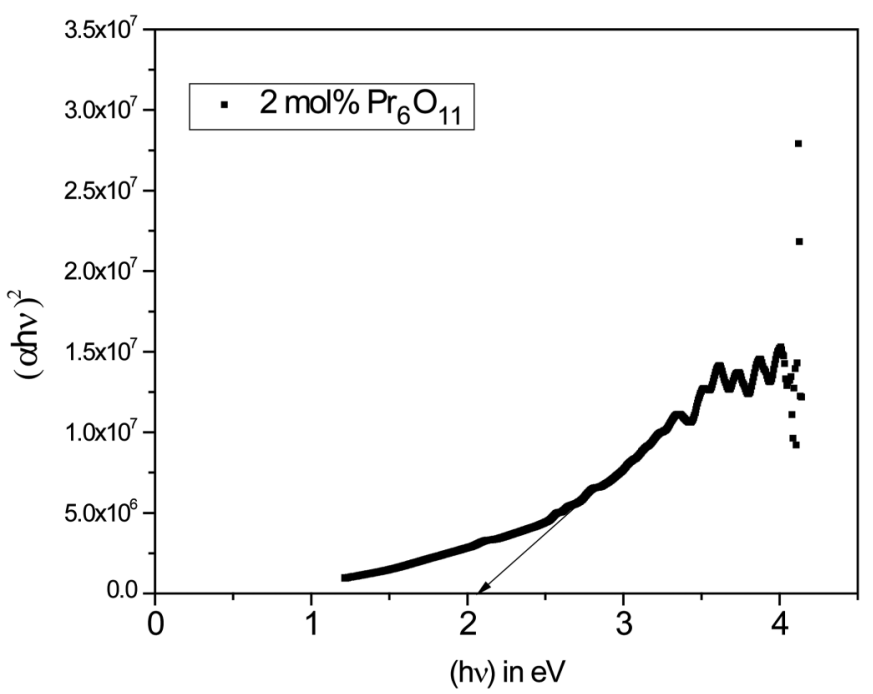

molar volume at 2 and $4 \mathrm{~mol} \%$ of $\operatorname{Pr}_{6} \mathrm{O}_{11}$ have been observed. The changes seem to have occurred due to the structural changes in the glass matrix at 2 and 4 mol\% of $\operatorname{Pr}_{6} \mathrm{O}_{11}$. The energy band gap increases with increase of molar percent of $\operatorname{Pr}_{6} \mathrm{O}_{11}$ and also increases with decrease of $\mathrm{Ag}_{2} \mathrm{O}$ molar percent. This indicates that
Fig. 6. Optical energy band gap versus $\mathrm{Pr}_{6} \mathrm{O}_{11}$ molar percent.

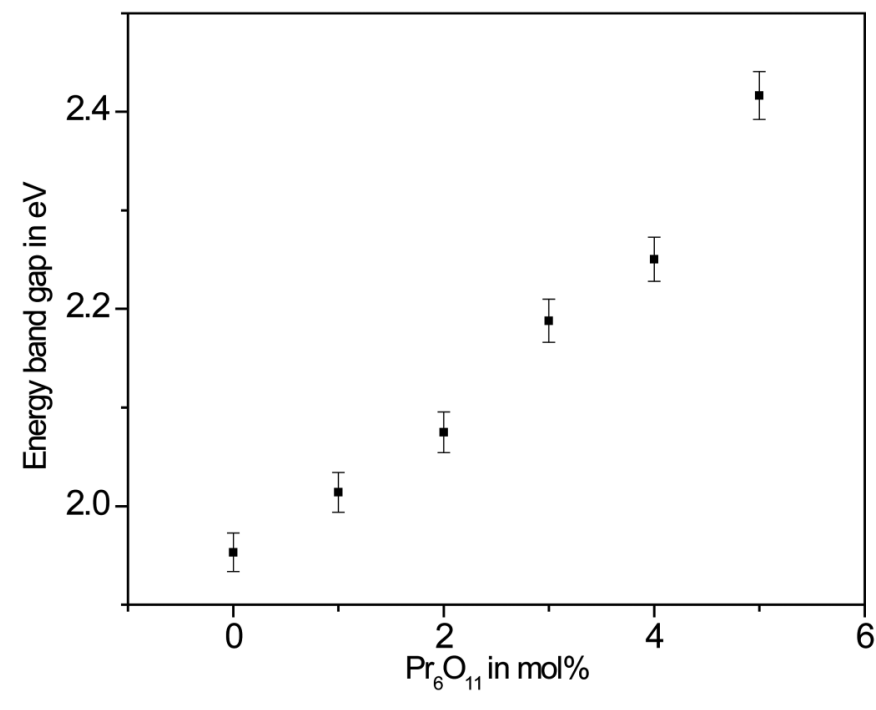

the addition of divalent oxides depolarize the glass forming network $\left(\mathrm{B}_{2} \mathrm{O}_{3}\right)$. The trend of refractive index, molar refraction, and polarizability variations with concentration of rare earth oxide is as expected. In this study the significant changes occurred not only due to the insertion of rare earth ions but also due to insertion of $\mathrm{Ag}^{2+}$ ions.

\section{References}

1. Y.C. Ratnakaram, A. Vijayakumar, and R.P.S. Chakradhar. J. Lumin. 118, 227 (2006). doi:10.1016/j.jlumin.2005.08.015.

2. N.J. Kreidl. J. Non-Cryst. Sol. 123, 377 (1990). doi:10.1016/0022-3093(90)90810-9.

3. A. Mekki, K.A. Ziq, D. Holland, and C.F. McConville. J. Magn. Magn. Mater. 260, 60 (2003). doi:10.1016/S0304-8853(02)00568-1.

4. S.D. Patil, V.M. Jali, and R.V. Anavekar. J. Mater. Sci. 31, 631 (2008).

5. J. Singh and G. Singh. Asian J. Chem. 21, S153 (2009).

6. F. Urbach. Phys. Rev. 92, 1324 (1953). doi:10.1103/PhysRev.92.1324

7. C.A. Hogarth and A.A. Hosseini. J. Mater. Sci. 18, 2697 (1983). doi:10.1007| BF00547586.

8. N.F. Mott and E.A. Davis. Philos. Mag. 28, 903 (1970).

9. S.K.J. Al-Ani and A.A. Higazy. J. Mater. Sci. 26, 3670 (1991). doi:10.1007| BF00557161.

10. B. Eraiah and S.G. Bhat. J. Phys. Chem. Sol. 68, 581 (2007). doi:10.1016/j.jpcs. 2007.01.032.

11. V. Dimitrov and S. Sakka. J. Appl. Phys. 79, 1736 (1996). doi:10.1063/1.360962.

12. M. Tsuda, S. Soga, H. Inoue, and A.N. Makishima. J. Appl. Phys. 85, 29 (1999). doi:10.1063/1.369445.

13. K. Tanaka, N. Tatehata, K. Fujita, and K. Hirao. J. Phys. D, 31, 2622 (1998). doi:10.1088/0022-3727/31/19/035.

14. Y.C. Ratnakram, D.T. Naidu, A. Vijayakumar, and J.L. Rao. J. Phys. Condens. Matter, 16, 3779 (2004). doi:10.1088/0953-8984/16/21/026.

15. Z. Rizwan, M.G.M. Sabri, and B.Z. Azmi. Int. J. Phys. Sci. 6(1), 79 (2011).

16. C.A. Hogarth and M.A. Ghauri. J. Mater. Sci. 14, 1641 (1979). doi:10.1007| BF00569284.

17. B.D. McSwain, N.F. Borrel, and S.V. Gongjen. Phys. Chem. Glasses, 4, 1 (1963). 